\title{
INFLUÊNCIA DAS MÍDIAS SOCIAIS NA PERCEPÇÃO DE ALUNOS DO ENSINO MÉDIO DA REGIÃO TOCANTINA DO MARANHÃO SOBRE A PANDEMIA COVID-19
}

\author{
Influence of Social Media on the Perception of High School Students in the Tocantine Region of \\ Maranhão about Pandemic Covid-19
}

\section{Renato Correia Lima ${ }^{1}$ [renatocorreia.lima@hotmail.com]}

\section{Vinícius Rocha da Silva² [viniciusbiologo10@ hotmail.com]}

\begin{abstract}
${ }^{1}$ Secretaria de Educação do Governo do Estado do Maranhão - Unidade Regional de Imperatriz Rua Simplício Moreira - Nova Imperatriz, Imperatriz - MA, 65900-550; Doutorando em Genética Conservação e Biologia Evolutiva do Instituto Nacional de Pesquisas na Amazônia - Av. André Araújo, 2936 - Petrópolis, Manaus - AM, 69067-375

${ }^{2}$ Universidade Estadual da Região Tocantina do Maranhão, Campus de Imperatriz, Rua Godofredo Viana, 1300 - Centro, Imperatriz - MA, CEP 65900-000
\end{abstract}

Recebido em: 05/05/2020

Aceito em: 13/10/2020

\section{Resumo}

Coronavírus são vírus de RNA que causam infecções respiratórias em vários animais, entre eles aves e mamíferos. O novo coronavírus (SARS-CoV-2) causador da doença COVID-19, foi detectado em Wuhan, na China e teve uma disseminação explosiva fazendo com que a OMS declarasse situação de emergência de saúde internacional. Nesse cenário, o presente estudo objetivou avaliar a percepção de alunos do ensino médio sobre a pandemia COVID-19. Para tanto, um questionário contendo 10 perguntas fechadas foi aplicado a 99 alunos da rede pública da cidade de Imperatriz, Maranhão, entre os dias 22 e 27 de abril de 2020 por meio da plataforma de pesquisas Survio. As análises estatísticas foram feitas por meio do software SigmaPlot para realizar os testes de correlações de Spearman. Os alunos que se informam prioritariamente através das mídias sociais tenderam a acreditar que o Sars-CoV-2 foi criado em laboratório (valor de p 0,0384), a praticar menos medidas de contenção contra a disseminação do vírus (valor de p 0,00105) e a defender o uso indiscriminado da hidroxicloroquina por todos os infectados (valor de p 0,0282). Recomenda-se, portanto, o combate a fake news e incentivo ao conhecimento científico.

Palavras-chave: Sars-Cov-2; fake news; Imperatriz/MA.

\begin{abstract}
Coronaviruses are RNA viruses that cause respiratory infections in various animals, including birds and mammals. The new coronavirus (SARS-CoV-2) that causes COVID-19 disease, was detected in Wuhan, China, and had an explosive spread causing a WHO to declare a situation of international health loss. In this scenario, the present study aimed to assess the perception of high school students about a pandemic COVID19. To this end, a questionnaire containing 10 questions was applied to 99 public school students in the city of Imperatriz, in Maranhão, through the Survio research platform. As statistical statistics made using the SigmaPlot software to perform Spearman's correlation tests. Students who primarily inform the use of social media to believe that Sars-CoV-2 was created in the laboratory ( $\mathrm{p}$ value 0.0384 ), practice less containment measures against the spread of viruses $(\mathrm{p}$ value 0,00105$)$ and the defender or indiscriminate use of hydroxychloroquine by all those infected ( $\mathrm{p}$ value 0.0282). It is therefore recommended to combat false news and encourage scientific knowledge.
\end{abstract}

Keywords: Sars-Cov-2; fake news; Imperatriz/MA. 


\section{INTRODUÇÃO}

Tomando como referência o papel das pandemias na história humana é possível identificar um componente negativamente inflexível na dinâmica demográfica a partir de uma clara periodização de eventos com amplas repercussões epidemiológicas que remonta os primórdios dos primeiros grupos humanos e que vem até os dias atuais (SENHORAS, 2020).

De acordo com Senhoras (2020), observa-se que as pandemias mais notáveis e com amplas repercussões espaço-temporais na demografia humana são identificadas por uma periodização de eventos destacadas principalmente na literatura ocidental, embora sem precisão estatística, partindo do século VI com a conhecida "Praga de Justiniano", passando pelo século XIV com a "Peste Negra", até se chegar no século XX com a "Gripe Espanhola".

Sabe-se ainda que junto com a pandemia vem também a crise que afeta as populações nas mais diferentes escalas - desde a escala do indivíduo até a escala global - e das mais diferentes formas - como crises de saúde, crises econômicas, crises políticas, entre outras. Cada uma dessas crises produz impactos diferentes nas sociedades e exige medidas específicas para lidar com as mesmas. Deve-se perceber, porém, que estas, muitas vezes, podem ser diretamente relacionadas, seja por causas comuns ou pelas ações necessárias para a resolução de cada uma delas, que podem ser complementares e abrir possibilidades que não costumam ser vislumbradas (MENDES \& MARQUES, 2016).

A mais recente pandemia está relacionada ao grupo do Coronavírus que são vírus de RNA que causam infecções respiratórias em vários animais, entre eles aves e mamíferos (FEHR \& PERLMAN, 2020). Sete coronavírus são reconhecidamente patógenos nos seres humanos, dentre os quais ocorrem os sazonais que estão frequentemente associados a síndromes gripais. Nas últimas duas décadas, dois deles foram protagonistas de epidemias extremamente virulentas, como a síndrome respiratória aguda grave (SARS) que surgiu na China, em 2003, e a síndrome respiratória do Oriente Médio (MERS) que emergiu na Arábia Saudita em 2012 (WORLD HEALTH ORGANIZATION, 2020).

O novo coronavírus, denominado SARS-CoV-2, causador da doença COVID-19, foi detectado em 31 de dezembro de 2019 em Wuhan, na China, epicentro de propulsão da pandemia, e rapidamente disseminado para demais países como Japão, Estados Unidos, Canadá, Austrália e Brasil, o que fez com que a OMS declarasse, em 30 de janeiro, a epidemia uma emergência internacional (PHEIC) (LANA et al., 2020). Dentro desse cenário, vale ressaltar a influência das mídias sociais na percepção das pessoas já que constituem um veículo com notável facilidade de disseminação e construção do conhecimento. Por essa característica, elas são usadas para rápida disseminação de notícias falsas, sobretudo, quando existe muita incerteza e alta demanda por informações públicas sobre questões como crises (SPENCE et al.,2016; JANG \& KIM, 2018) e preocupação com a saúde (JANG et al., 2017).

O estudo baseado na percepção é de extrema importância, pois, baseia-se na interpretação que o indivíduo faz diante dos acontecimentos da realidade. Percepção essa que é peculiar, cada pessoa percebe um objeto ou uma situação de acordo com os aspectos que têm especial relevância para si própria (REIS \& FARIA, 2016). Sendo assim, entender a visão dos alunos sobre um fenômeno importante como a atual pandemia pode ajudar na escolha de foco e abordagens a serem trabalhados na escola. Diante disso, o objetivo do presente trabalho foi analisar a percepção dos alunos de ensino médio no que diz respeito à pandemia do novo Coronavírus. 


\section{METODOLOGIA}

Foi entrevistado um total de 99 alunos de duas escolas da rede estadual de educação do estado do Maranhão, 52 estudantes do Centro de Ensino Estado de Goiás (CEEG) e 47 do Centro de Ensino Dorgival Pinheiro de Sousa (CEDPS), entre os dias 22 e 27 de abril de 2020 por meio da plataforma de pesquisas Survio (www.survio.com). Foram feitas 10 perguntas fechadas (Tabela 1) para avaliar a percepção dos educandos sobre a pandemia Covid-19 das quais três permitiam mais que uma resposta (3, 8 e 9) e as outras uma única resposta. A partir das respostas, a plataforma Survio foi utilizada para plotar os gráficos em cada pergunta e o software SigmaPlot para realizar os testes de correlações de Spearman. Para os testes feitos no SigmaPlot, foi necessária a substituição das respostas objetivas por números.

Tabela 1. Perguntas feitas para alunos do ensino médio da rede pública de educação da região Tocantina do Maranhão através da plataforma Survio para avaliar a percepção deles sobre a pandemia Covid-19.

\begin{tabular}{cl}
\hline $\mathbf{N}^{\mathbf{0}}$ & \multicolumn{1}{c}{ PERGUNTAS } \\
\hline 1 & Em qual escola você estuda? \\
2 & Qual série você está cursando atualmente? \\
3 & $\begin{array}{l}\text { Qual(ais) fonte(s) de informação você mais utiliza para se atualizar sobre o novo Coronavírus } \\
\text { (Sars-Cov-2), causador da COVID-19? }\end{array}$ \\
4 & $\begin{array}{l}\text { Na sua opinião, o conhecimento que você obteve na escola, em especial nas aulas de Ciências } \\
\text { e Biologia, ajudaram-lhe a entender e enfrentar essa pandemia? }\end{array}$ \\
5 & Você já leu algum artigo científico sobre o novo Coronavírus? \\
6 & $\begin{array}{l}\text { De acordo com seu senso crítico, qual das alternativas abaixo está mais próxima de explicar a } \\
\text { origem do novo Coronavírus? }\end{array}$ \\
7 & $\begin{array}{l}\text { Você concorda que o surgimento de um novo vírus como o Sars-Cov-2 pode ser considerado } \\
\text { uma evidência que ajuda a confirmar a teoria da evolução biológica proposta por Charles }\end{array}$ \\
Darwin? & $\begin{array}{l}\text { Qual a sua opinião sobre os métodos de prevenção contra a disseminação do novo Coronavírus } \\
\text { recomendados pela Organização Mundial de Saúde (OMS), tais como: isolamento social, uso } \\
\text { de máscaras e higiene frequente das mãos? }\end{array}$ \\
9 & $\begin{array}{l}\text { Quais as medidas de proteção contra o COVID-19 você está pondo em prática no seu dia a } \\
\text { dia? }\end{array}$ \\
10 & $\begin{array}{l}\text { Falou-se bastante que a hidroxicloroquina seria um medicamento capaz de curar a COVID-19. } \\
\text { Na sua opinião, esse medicamento pode ser usado por todos os infectados na tentativa de curar } \\
\text { a doença? }\end{array}$
\end{tabular}

As perguntas que permitiam mais que uma resposta foram abordadas da seguinte forma: as respostas da pergunta 3 foram separadas em três grupos. Ao aluno que respondeu se informar principalmente por meios que não possuem base científica ou que não possui supervisão para evitar notícias falsas (a Bíblia e mídias sociais) foi atribuído o número 0. Ao aluno que disse se informar por ao menos um veículo de informação que tenha supervisão contra notícias falsas (televisão, rádio, site de jornal ou jornal impresso) foi atribuído o número 1. E ao que tem como principal meio de informação pelo menos um veículo de fonte diretamente científica (sites de revistas científicas e artigos científicos) foi atribuído o número 2.

Na questão 8, para quem escolheu a alternativa "não sei" foi atribuído o número 0. Para quem escolhem apenas a alternativa "são importantes para que vidas sejam salvas, mas não podem ser praticados para que a economia não pare" foi atribuído o número 1. Para quem escolheu tanto a opção "São importantes para que vidas sejam salvas, mas não podem ser praticados para que a economia não pare" como a opção "São importantes para que vidas sejam salvas e devem ser 
praticados" foi atribuído o número 2 e para quem escolheu apenas a alternativa "São importantes para que vidas sejam salvas e devem ser praticados" foi atribuído o número 3.

Em relação à pergunta 9, aos alunos que assumiram que não estão praticando nenhuma medida de contenção da disseminação da Covid-19 recomendado pela OMS foi atribuído o número 0 . Para aqueles que disseram estar praticando apenas uma medida de contenção foi atribuído o número 1, aos que disseram estar praticando duas medidas de contenção foi atribuído o número $2 \mathrm{e}$ aos que disseram estar praticando três medidas de contenção foi atribuído o número 3.

\section{RESULTADOS E DISCUSSÃO}

\section{Análise Geral das Respostas}

As duas maiores fontes de informação usadas pelos alunos foram televisão $(83,8 \%)$ seguida pelas mídias sociais (42,4\%), enquanto apenas $8,1 \%$ informam-se através de artigos científicos e $7,1 \%$ por revistas científicas. Isso revela grande distanciamento das fontes genuinamente científicas pelos alunos (Figura 1a)

A maioria $(83,8 \%)$ considera que as medidas de contenção recomendadas pela OMS contra a disseminação da pandemia do Covid-19 são importantes e devem ser praticadas (Figura 1d). A soma dos valores de porcentagem para as perguntas 3, 8 e 9 ultrapassam 100\% porque para essas perguntas foi possível escolher mais que uma alternativa como resposta.

A maior parte dos alunos $(45,5 \%)$ acredita que o Sars-CoV-2 foi produzido em laboratório (Figura 1b). Isso mostra distanciamento do conhecimento científico por parte dos alunos, pois essa hipótese já foi refutada (ANDERSEN et al., 2020). Apesar de serem assuntos relacionados, 59,2\% dos educandos também concorda que o surgimento do Sars-CoV-2 pode ser considerado uma evidência da teoria da evolução biológica proposta por Charles Darwin (Figura 1c). Essa incoerência entre as respostas pode demonstrar confusão nos conceitos de evolução orgânica e seleção artificial. Isso corrobora com os problemas de compreensão da teoria evolutiva por alunos do ensino médio constatados por Oliveira (2015). 


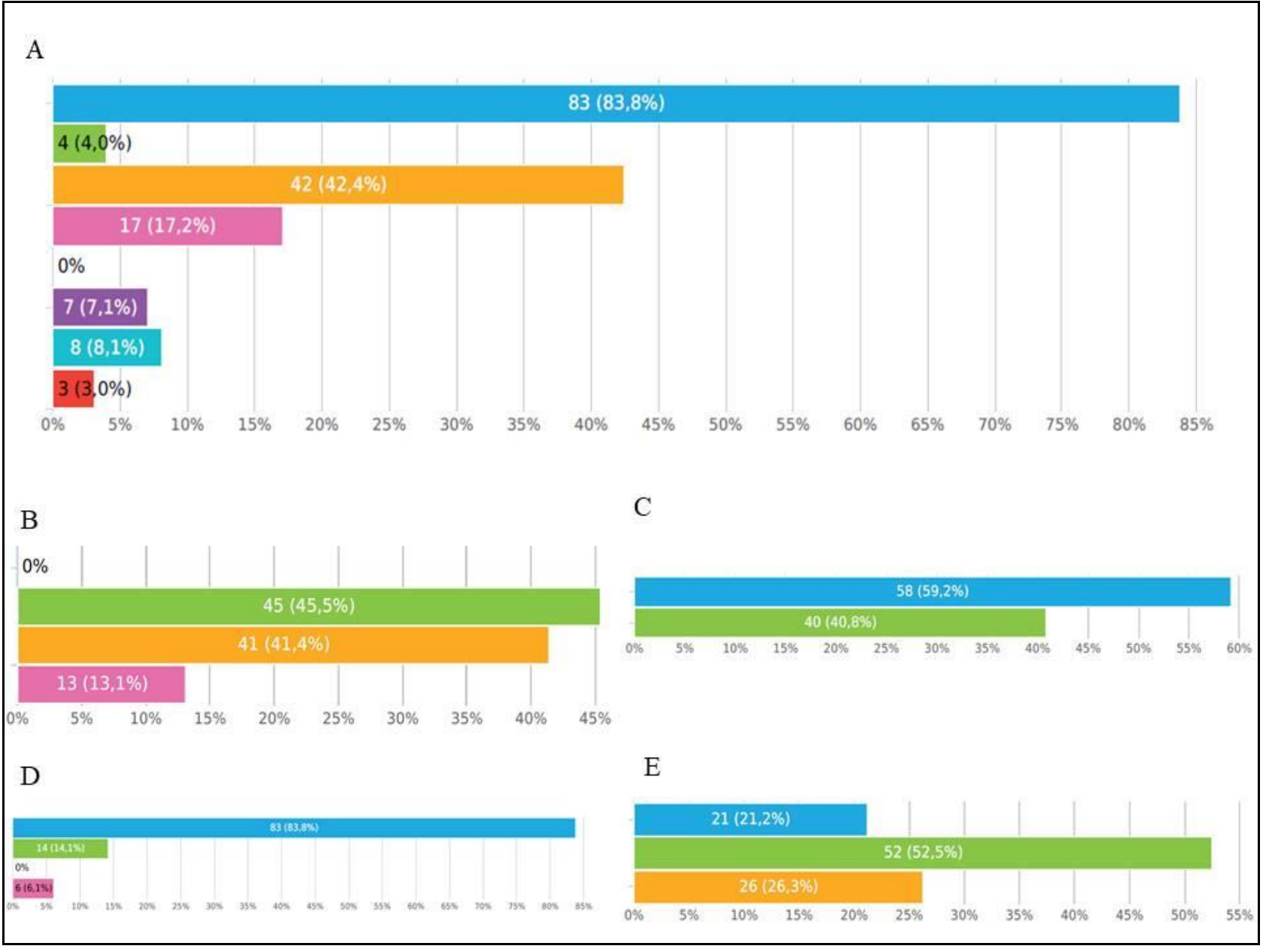

Figura 1) Gráficos que mostram o perfil da percepção dos alunos de escolas de Imperatriz/MA sobre a pandemia da Covid-19. A) Porcentagens das respostas para pergunta 3: 3\% a Bíblia (vermelho); 8,1\% artigos científicos (azul claro); 7,1\% sites de revistas científicas (lilás); 17,2\% sites de jornal ou jornais impressos (rosa); 42,4\% mídias sociais (laranja); 4\% rádio (verde) e 83,8\% televisão (azul escuro). B) Porcentagem das repostas para a pergunta 6: 13,1\% praga divina (rosa); 41,4\% surgimento de forma natural através de mutações genéticas (laranja) e 45,5\% criação em laboratório (verde). C) Porcentagem das repostas para a pergunta 7: 40,8\% não concordam (verde) e 59,2 concordam. D) Porcentagem das repostas para a pergunta 8: 6,1\% não sabem se é importante ou não (rosa); $14,1 \%$ consideram as medidas de proteção importantes, mas não devem ser praticadas devido o prejuízo à economia (verde) e 83,8\% consideram as medidas de proteção importantes e devem ser praticadas. E) Porcentagem das repostas para a pergunta 10: 26,3\% defendem que, independente de evidências científicas, o medicamento pode ser administrado por todos os infectados (amarelo); 52,5\% defendem que ainda não há evidências científicas que comprovem nem a sua eficácia nem a sua segurança a todos (verde) e $21,2 \%$ defendem que já a evidências científicas suficientes de que todos os infectados podem administrar o medicamento.

A porcentagem de alunos que são cautelosos em relação ao uso hidroxicloroquina por pacientes da Covid-19 (Figura 1e), a partir do entendimento de que não há evidências que comprovem sua eficácia e segurança, mostrou-se um pouco superior $(52,5 \%)$ ao somatório dos que defendem o uso desse medicamento por todos os infectados $(47,5 \%)$ seja pelo argumento de que isso independe das evidências científicas, pois, trata-se de um caso de vida ou morte (26,3\%); seja porque entendem que já existem evidências científicas suficientes para tanto $(21,2 \%)$.

Quase metade dos alunos, portanto, não reconhece os efeitos nocivos que o tratamento com hidroxicloroquina pode causar em parte dos pacientes, mesmo que estudos os tenham apontado antes da realização da entrevista no presente trabalho. Tais efeitos podem variar desde a prolongação do intervalo QTc (especialmente em pacientes com doenças cardíacas preexistentes ou se for prescrito associado a azitromicina), arritmias cardíacas, hipoglicemia, efeitos 
neuropsiquiátricos, interações droga-droga e reações de hipersensibilidade idiossincráticas (PASTICK et al., 2020; JUURLINK, 2020).

\section{Análise das Correlações entre as Perguntas}

Houve diferença entre a percepção dos estudantes das duas escolas analisadas sobre a importância do que se aprende no ambiente escolar, em especial nas aulas de Ciências e Biologia, para o melhor entendimento e/ou enfrentamento da pandemia Covid-19. A percepção dos alunos do CEDPS de que a aprendizagem escolar se mostrou importante para melhor entender e enfrentar a pandemia foi maior do que essa percepção dos estudantes do CEEG (perguntas 1 e 4 - Tabela 2). Essa correlação pode indicar, além de maior êxito do CEDPS em preparar os alunos para problemas reais, a ocorrência de problemas estruturais ou de recursos humanos no CEEG que precisam ser investigados mais a fundo.

Tabela 2. Perguntas das quais as respostas tiveram correlação significativa (valor de $p<0,05$ ) através do teste de correlação de Spearman realizado com o auxílio do software SigmaPlot a partir de entrevista feita em escolas da rede pública da região Tocantina do Maranhão.

\begin{tabular}{cccc}
\hline Número das perguntas que tiveram correlações* & Valor de $\mathbf{p}$ & Coeficiente de correlação \\
\hline 1 & 4 & 0,00117 & 0,323 \\
2 & 5 & 0,0176 & 0,238 \\
2 & 8 & 0,0118 & 0,253 \\
3 & 6 & 0,0384 & 0,209 \\
3 & 9 & 0,00105 & 0,326 \\
3 & 10 & 0,0282 & 0,221 \\
6 & 9 & 0,00857 & 0,263 \\
7 & 9 & 0,0345 & 0,214 \\
9 & 8 & 0,000235 & 0,364 \\
\hline
\end{tabular}

* As duas colunas contêm as numerações das perguntas que quando comparadas entre si apresentaram valores $\mathrm{p}$ de correlação significativos.

Houve correlação entre as perguntas 2 e 5 (Tabela 2), o que mostra há uma tendência de alunos que estão a mais tempo no ensino médio lerem algum conteúdo científico referente ao novo Coronavírus. Essa relação pode refletir a importância de continuidade da formação escolar para o desenvolvimento do senso crítico, como foi encontrado por (BORGES \& BARROS, 2015).

O entendimento de que o novo Coronavírus surgiu de forma natural esteve correlacionado com ações de contenção da disseminação da pandemia de Covid-19, de forma que, estatisticamente, quem reconhece o surgimento do vírus de forma natural tende a adotar mais medidas de proteção, tais como o isolamento social, o uso de máscara e a higienização frequente das mãos. (perguntas 6 e 9 - Tabela 2).

Aqueles que concordam que o surgimento do novo Coronavírus pode ser considerado uma evidência da teoria da Evolução Orgânica tenderam a tomar ao menos uma medida de contenção da disseminação do novo Coronavírus (perguntas 7 e 9 - Tabela 2). Dessa forma, o não reconhecimento da atuação da seleção natural no surgimento do vírus está associado à ausência de medidas de contenção contra o Sars-CoV-2.

A pergunta 3 foi a que se correlacionou com maior número de outras questões $(6,9$ e 10 Tabela 2), o que demonstra que o tipo de fonte informativa buscada pelos alunos teve impacto significativo na percepção deles. A correlação entre as perguntas 3 e 6 indica que os alunos que tiveram mais acesso a conteúdos científicos (sites de revistas científicas e artigos científicos) não acreditam na teoria conspiratória que defende que o novo Coronavírus fora produzido em laboratório e entendem que o Sars-CoV-2 surgiu de forma natural através de mutações genéticas, como constatou Andersen et al. (2020). 
A substancial facilidade de disseminação e construção de conhecimento das redes sociais (HARA e SANFILIPPO, 2016; PARK, 2017) é uma possível explicação a maior vulnerabilidade a teorias conspiratórias por aqueles alunos que se informam principalmente através das mídias digitais, pois, através desses veículos de comunicação, as notícias falsas, que interferem no mundo real ao mudar o comportamento das pessoas, são mais rapidamente espalhadas, sobretudo, quando existe muita incerteza e alta demanda por informações públicas sobre questões como crises (SPENCE et al.,2016; JANG \& KIM, 2018) e preocupação com a saúde (JANG et al., 2017). Cenário esse vivenciado durante a pandemia do Covid-19.

Além de entenderem melhor a provável origem do Sars-CoV-2, os alunos que mais leem conteúdo científico também praticam maior número das medidas de contenção recomendadas pela a OMS contra a disseminação do novo Coronavírus, em relação àqueles que se informam principalmente através de mídias sociais (perguntas 3 e 9 - Tabela 2).

A correlação entre as perguntas 3 e 10 (Tabela 2) indica que alunos que se basearam em fontes que não têm revisão contra notícias falsas e/ou não científicas, como as mídias sociais, entenderam que a hidroxicloroquina pode ser usada indistintamente pelos infectados seja porque, na visão deles, já há evidências científicas suficientes, seja porque defendem que isso independe de evidências científicas já que se trata de um caso de vida ou morte.

O elo entre informações provenientes de mídias sociais e a crença precoce na hidroxicloroquina como solução dos problemas relacionados a Covid-19 (ou parte deles) reforça o potencial nocivo das redes sociais. Sendo que, mesmo sem consenso científico, o presidente do Brasil causou esperança desmedida nesse medicamento ao defender seu uso (JORNAL NACIONAL, 2020) baseando-se, à época, em estudo que analisou apenas 20 pacientes (GAUTRET et al., 2020). Ainda que estudo posterior ao pronunciamento do presidente tenha mostrado antagonismo da hidroxicloroquina contra o Covid-19 in vitro, a evidência dos efeitos em pacientes foi limitada (CHEN et al., 2020).

Além da falta de consenso sobre a eficácia da hidroxicloroquina, essa droga pode ter graves efeitos coletarias, sobretudo para quem sobre de problemas cardíacos, podendo levar a óbito (PASTICK et al., 2020; JUURLINK, 2020). Isso revela precocidade dos leigos em confiar na eficiência e segurança desse medicamento. Em contrapartida, os alunos que mais se basearam em fontes científicas manifestaram maior cautela sobre o uso indiscriminado do medicamento, pois defenderam que não há evidências científicas suficientes sobre sua eficácia e segurança.

Os alunos do CEDPS tenderam a reconhecer maior importância nas medidas de contenção contra a disseminação do Covid-19 recomendadas pela OMS (correlação entre as perguntas 2 e 8). Isso, mais uma vez, pode indicar dificuldades enfrentadas pelo CEEG no processo de ensino aprendizagem que precisam ser investigadas mais profundamente (Tabela 2).

O reconhecimento da importância das medidas de contenção contra a disseminação do Covid-19 recomendadas pela OMS esteve, naturalmente, correlacionado positivamente com o comportamento de alunos que tomam ao menos uma das medidas de contenção (perguntas 8 e 9). Assim, os alunos que consideram as medidas de contenção importantes tendem a tomar pelo menos um destas medidas: isolamento social, uso de máscara ou higienização frequente das mãos (Tabela 2).

\section{CONCLUSÃO}

A maior parte dos estudantes informa-se em primeiro lugar através da televisão seguido das mídias sociais, enquanto pouquíssimos têm acesso a fontes genuinamente científicas. Apesar disso, a maioria deles reconheceu a importância das medidas de contenção contra a disseminação da Covid-19. 
A informação baseada em mídias sociais está relacionada à crença na teoria conspiratória que defende que o Sars-CoV-2 fora criado em laboratório (já refutada pela ciência), bem como a menor prática de medidas de proteção contra a disseminação da COVID-19 e também a ideia de que a hidroxicloroquina pode ser usada por todos os infectados indistintamente. Recomenda-se às escolas analisadas no presente trabalho, portanto, que atuem mais fortemente no combate às notícias falsas, bem como no incentivo ao conhecimento científico para melhor compreensão e enfrentamento da pandemia Covid-19.

\section{REFERÊNCIAS}

ANDERSEN, K. G.; RAMBAUT, A.; LIPKIN W. I; HOLMES, E. C. e GARRY R. F. (2020). The proximal origin of SARS-CoV-2. Nature Medicine, vol. 26, p. 450-455.

CHEN, Z;; Hu, JIJIA.; ZHANG, Z.; JIANG, S.; HAN, S.; YAN, D.; ZHUANG, R.; HU, Ben e ZHANG, Z. (2020). Efficacy of hydroxychloroquine in patients with COVID-19: results of a randomized clinical trial. MedRxiv preprint. doi: https://doi.org/10.1101/2020.03.22.20040758.

BORGES, I. A. B. G \& BARROS, A. L. E. C. (2015). Desenvolvimento do Senso Crítico do Aluno. Revista Philologus. Rio de Janeiro,

LANA, R. M.; COELHO, F. C.; GOMES, M. F. da C.; CRUZ, O. G.; BASTOS, L. S.; VILLELA, D. A. M. CODEÇO, C. T. (2020). Emergência do novo Coronavírus (Sars-CoV-2) e o papel de uma vigilância nacional em saúde oportuna e efetiva. Cadernos de Saúde Pública 36(3) DOI: 1590/0102311 X00019620.

FEHR, A. R. \& PERLMAN, S. (2015). Coronaviruses: an overview of their replication and pathogenesis. Methods Mol Biol, 1282:1-23.

HARA, N.; SANFILIPPO, M. R. (2016). Co-constructing controversy: Content analysis of collaborative knowledge negotiation in online communities. Information, Communication \& Society, 19(11), 1587e1604.

GAUTRET, P.; LAGIER, J.; PAROLA, P.; HOANG, V. T.; MEDDEB, L.; MAILHE, M.; DOUDIER, B.; COURJON, J.; GIORDANENGO, V.; VIEIRA, V. E.; DUPONT, H. T.; HONORÉ, S.; COLSON, P.; CHABRIÈRE, E.; LA SCOLA, B.; ROLAIN J.; BROUQUI P. e RAOULT, D. (2020). Hydroxychloroquine and azithromycin as a treatment of COVID-19: results of an open-label non-randomized clinical trial. International Journal of Antimicrobial Agents - In Press.- DOI : 10.1016/j.ijantimicag.2020.105949.

JANG, S. M. \& KIM, J. K. (2018). Third person effects of fake news: Fake news regulation and media literacy interventions. Computers in Human Behavior. 80 p. 295 - 302.

JANG, S. M., MCKEEVER, B., MCKEEVER, R., e KIM, J. K. (2017). From social media to mainstream news: The information flow of the vaccine-autism controversy in the US, Canada, and the UK. Health Communication. https://doi.org/10.1080/10410236 (in press).

JUURLINK. D. N. (2020). Safety considerations with chloroquine, hydroxychloroquine and azithromycin in the management of SARS-CoV-2 infection. CMAJ. 192:E450-3. DOI: 10.1503/cmaj.200528.

JORNAL NACIONAL. (2020). Em pronunciamento, Bolsonaro defende uso da cloroquina para tratamento do coronavírus. Rio de Janeiro, 08 de abril de 2020. Disponível em: < https://g1.globo.com/jornal-nacional/noticia/2020/04/08/em-pronunciamento-bolsonaro-defendeuso-da-cloroquina-para-tratamento-do-coronavirus.ghtml>. Acesso em: 02 de maio de 2020. 
MENDES, T. M. \& MARQUES, T. S. (2020). Entre Epidemias e Pandemias. (2020). As diferentes dimensões da crise do Ébola 2013/2016. 2016. ISBN 978-84-944193-3-1. Disponível em: https://repositorio-aberto.up.pt/bitstream/10216/86676/2/160913.pdf. Acesso em: 25 abril 2020.

OLIVEIRA, G. S. (2015). Darwin na Escola: Relato de uma Experiência de Divulgação Científica. Rev. Cult. e Ext. USP, São Paulo, n. 12, supl., p.57-71, mar.

WORLD HEALTH ORGANIZATION. (2020). IHR procedures concerning public health emergencies of international concern (PHEIC). http://www.who. int/ihr/procedures/pheic/en/. Acesso em 29 de Jan. 2020.

PARK, Y. J. (2017). Social antecedents and consequences of political privacy. New Media \& Society. https://doi.org/10.1077/1461444817716677.

PASTICK, K. A; OKAFOR, E. C.; WANG, F.; LOFGREN, S. M.; SKIPPER, C. P.; NICOL, M. R.; PULLEN, M. F.; RAJASINGHAM, R.; McDONALD E. G.; LEE, T. C.; SCHWARTZ, I. S.; KELLY, L. E.; LOTHER, S. A.; MITJÀ, O.; LETANG, E.; ABASSI M. e BOULWARE, D. R. (2020). Review: Hydroxychloroquine and Chloroquine for Treatment of SARS-CoV-2 (COVID19). Open Forum Infectious Diseases. DOI: 10.1093/ofid/ofaa130.

REIS, I. F. \& FARIA, F. L. (2016). A percepção de professores e alunos do ensino médio sobre a atividade estudo de caso. Ciênc. Educ., Bauru, v. 22, n. 2, p. 319-333. DOI: http://dx.doi.org/10.1590/1516-731320160020004.

SENHORAS, E. M. (2020). Coronavírus e o papel das pandemias na história humana. ano II, vol. 1, n. 1, Boa Vista. 2020. Disponível em: https://revista.ufrr.br/boca/article/view/Eloi/2899. Acesso em 24 de abril 2020.

SPENCE, P. R., LACHLAN, K. A., EDWARDS, A., e EDWARDS, C. (2016). Tweeting fast matters, but only if I think about it: Information updates on social media. Communication Quarterly, 64(1), 55e71. 